\title{
Posterior External Jugular Vein
}

National Cancer Institute

\section{Source}

National Cancer Institute. Posterior External Jugular Vein. NCI Thesaurus. Code C33360.

A vein that drains the superficial muscles and integument of the upper back portion of the neck into the external jugular vein. 